\title{
Os entregadores de aplicativos e a fragmentação da classe trabalhadora na contemporaneidade
}

\author{
Nathalia Tamiris Carvalho de Luna ${ }^{1}$ \\ https://orcid.org/0000-0002-0520-5000
}

\author{
Ariadne Samila Martins de Oliveira ${ }^{2}$ \\ https://orcid.org/0000-0001-9132-1835
}

${ }^{1}$ Universidade Federal de Pernambuco, Departamento de Serviço Social, Curso de Graduação em Serviço Social, Recife, PE, Brasil

${ }^{2}$ Universidade Federal de Pernambuco, Departamento de Serviço Social, Curso de Graduação em Serviço Social, Recife, PE, Brasil

\section{Os entregadores de aplicativos e a fragmentação da classe trabalhadora na contemporaneidade}

Resumo: O artigo objetiva analisar os elementos teóricos-conceituais que estruturam as novas modalidades de trabalho, com foco nos entregadores de aplicativos, a partir da inserção das TICs no mundo do trabalho, da expansão do fenômeno da uberização e como esses processos interferem na organização coletiva dos trabalhadores. Trata-se de uma metodologia com base documental e bibliográfica. O artigo versa sobre as transformações ocorridas no mundo do trabalho, no contexto da indústria 4.0, que alavancou os níveis de acumulação, fazendo surgir o novo proletariado de serviços. Aborda também a relação da uberização e ideologia empreendedora que, por meio das empresas-aplicativo, tenta fragmentar a organização coletiva destes trabalhadores. As considerações finais apontam que, apesar da propagação da ideologia empreendedora e da inserção das TICs nos trabalhos uberizados, os entregadores de aplicativos vêm construindo lutas, revelando que está em curso uma nova fase da organização coletiva da classe trabalhadora.

Palavras-chave: Entregadores de Aplicativos; Lutas Coletivas; Tecnologias de Informação e Comunicação; Uberização.

\section{App delivery workers and the fragmentation of the contemporary working class}

Abstract: The article aims to analyze the theoretical and conceptual elements that structure the new modalities of work, focusing on the app delivery workers, from the insertion of ICTs in the world of work, the expansion of the phenomenon of uberization, and how these processes interfere with the collective organization of workers. This is a methodology with documentary and bibliographical basis. The article deals with the transformations that have occurred in the world of work, in the context of Industry 4.0, which has leveraged the levels of accumulation, giving rise to the new service proletariat. It also addresses the relationship between uberization and entrepreneurial ideology which, through app-companies, attempts to fragment the collective organization of these workers. The final considerations point out that despite the spread of entrepreneurial ideology and the insertion of ICTs in uberized work, the app delivery workers have been building struggles, revealing that a new phase of collective organization of the working class is underway.

Keywords: App delivery workers; Collective Struggles; Information and Communication Technologies; Uberization.

Recebido em: 01.07.2021. Aprovado em: 31.08.2021. Revisado em: 14.09.2021.

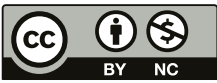

Este é um artigo publicado em acesso aberto (Open Access) sob a licença Creative Commons Attribution NonCommercial, que permite uso, distribuição e reprodução em qualquer meio, sem restrições desde que sem fins comerciais e que o trabalho original seja corretamente citado. 


\section{Introdução}

Tratamos aqui daquilo que vem sendo defendido como processo de uberização do trabalho e suas implicações para a classe trabalhadora. Embora o nome tenha origem na denominação da empresa Uber, este fenômeno revela uma tendência que perpassa o mundo do trabalho do século XXI e que, de forma global, vem atingindo diversas ocupações, como é o caso dos entregadores de aplicativos. Este artigo tem como objetivo analisar os elementos teóricos-conceituais que estruturam as novas modalidades de trabalho, em especial dos entregadores de aplicativos, a partir do fenômeno da uberização e da inserção das Tecnologias da Informação e Comunicação (TICs) no mundo do trabalho, bem como este processo de trabalho interfere na organização coletiva dos trabalhadores.

Para o desenvolvimento do artigo, realizamos um levantamento bibliográfico e documental. As reflexões aqui trazidas estão sustentadas no método materialista histórico-dialético, visto que este possibilita o entendimento da realidade a partir da categoria da totalidade concreta e não apenas do fenômeno isolado.

Este artigo está apresentado em dois itens fundamentais. O primeiro, versa sobre a indústria 4.0 que, ao mesmo tempo que alavancou os níveis de acumulação, ocasionou inúmeras transformações nas relações de trabalho, a partir das TICs, acarretando no aparecimento do novo proletariado de serviços. O segundo, trata sobre como o fenômeno da uberização e a ideologia empreendedora, por meio das empresas-aplicativo de delivery, tenta fragmentar a organização coletiva dos trabalhadores. Nas considerações finais, evidenciamos que está em curso uma nova fase da organização coletiva da classe trabalhadora.

\section{Indústria 4.0: Flexibilização, automatização e o trabalho digital}

É no contexto de crise permanente do capital - em curso desde a década de 1970 - que o capital busca novas formas e novos nichos para que possa se valorizar ainda mais e extrair lucros de forma exponencial. A partir disso, é preciso entender que esse contexto vem afetando o mundo do trabalho, visto que o uso da tecnologia implica diretamente no modo de produzir. Assim, a reestruturação capitalista "é impensável sem o mundo digital, é impensável sem a era do mundo financeiro que 'revolucionou' o tempo e o espaço em todas as atividades produtivas" (ANTUNES, 2018 apud FACHIN, 2018)'.

O trabalho e a tecnologia possuem uma relação histórica no capitalismo. A tecnologia é usada pelos donos dos meios de produção para aumentar as margens de lucro e diminuir a força de trabalho. Sabendo disso, o mundo do trabalho na conjuntura atual tem sido alvo de inúmeras inovações tecnológicas, tendo em vista os interesses do capital. É nesse cenário que se insere a Indústria 4.0 ou a Quarta Revolução Industrial como sendo um componente da reestruturação produtiva permanente do capital, que tem como centralidade a exploração e precarização dos trabalhadores - por meio do trabalho digital.

A Indústria 4.0, então, emerge na Alemanha, em 2011, e reúne um conjunto de propostas tecnológicas, dentre as quais se destacam, segundo Fagiani e Previtali (2020, p. 219) o:

desenvolvimento das tecnologias de informação e comunicação ( $\left.\mathrm{TICs}^{2}\right)$, o que possibilita a interconexão de sistemas ciberfísicos ao longo das cadeias de valor baseado na internet das coisas (IoT), nas big datas e na inteligência artificial, a qual permite que máquinas tomem decisões como seres humanos, ou seja, que robôs ou sistemas possam aprender e solucionar problemas com base em dados e protocolos de comunicação-padrão com grande rigidez e flexibilidade

Nesse contexto de Indústria $4.0^{3}$, está em curso o trabalho digital que, juntamente com as TICs, introduzem um novo modelo estrutural da gestão organizacional dos processos laborais contemporâneo. Modelo este marcado pela ampliação do trabalho morto - corporificado nas ferramentas e maquinarias mais robotizadas, sob a égide do comando do trabalho-informacional-digital - da intensificação da flexibilização e, consequentemente, da precarização da força de trabalho.

É nesse cenário que se faz presente a discussão sobre o incremento da acumulação flexível aliada à informatização $0^{4}$. Ao contrário do que anteriormente estava posto sobre uma automação rígida - pelos ditames do fordismo-taylorismo - no capitalismo contemporâneo, presencia-se a automação flexível, por meio do 
processamento rápido de dados e informações, através de plataformas digitais e algoritmos. Isto é retratado na passagem de Wolff (2009, p. 107), ao dizer que o modelo atual de empresa em rede tem:

uma estrutura organizacional integrada, flexível e enxuta e uma nova cultura produtiva com vistas a estimular o trabalhador a estar aberto a mudanças e afeito a compartilhar informações pertinentes à melhoria da produtividade. Para tanto, privilegia a fluidez da comunicação entre os processos de trabalho em detrimento do modelo vertical baseado em hierarquias rígidas, tal como recomenda o taylorismo mais clássico. (WOLFF, 2009, p. 107)

No caso do Brasil, em que pese as particularidades por ser uma economia dependente e periférica, a revolução 4.0, a robotização, a inteligência artificial e a automação nas relações de trabalho, não possuem o mesmo nível de desenvolvimento como ocorre nos países capitalistas mais desenvolvidos como o Japão, a Alemanha e o Reino Unido. Baseado nisso, o economista Bruno Ottoni explicita que:

O Brasil está bem atrás na Revolução 4.0. Os dados da Federação Internacional de Robótica, por exemplo, que acompanham o estoque de robôs industriais de diversos países, colocam o Brasil como estando na parte baixa dos rankings. Mais precisamente, o Brasil aparece na metade inferior do ranking de países quando é feita uma ordenação com base na quantidade de robôs industriais por milhares de trabalhadores (OTTONI, 2020 apud SANTOS, 2020, p. 1).

O que se presencia, então, com a indústria 4.0 e suas características de automação, robotização e inteligência artificial, é um maior aprofundamento na precarização estrutural do trabalho, em que há a redução e/ou aniquilamento de postos de trabalho e o forte incremento das máquinas no mundo produtivo, visando maiores lucros através da redução do tempo gasto no processo de produção. Segundo dados do Laboratório do Futuro (2019), da Universidade Federal do Rio de Janeiro (UFRJ), a automação ameaça mais da metade dos empregos em todos os 5.570 municípios do país até 2040.

Assim, o capitalismo da era digital abre vias para uma maior subsunção do trabalho ao capital, visto que as TICs são utilizadas como mecanismos de extração de mais-valor, a partir de um gerenciamento online da força de trabalho. Logo, é no capitalismo informacional-digital - permeado pelo amplo uso das TICs - que se ampliam novos espaços de geração de valor. Dentre eles, o setor de serviços que participa "das cadeias produtivas de valor, legando cada vez mais ao passado sua forma improdutiva para se converter em parte integrante do processo de geração (produtiva) do valor" (ANTUNES, 2018, p. 47).

A mercantilização do setor de serviços acontece, então, a partir da reestruturação produtiva e mundialização do capital, em que ocorre a "desestruturação da empresa fordista" e surge "como bem definiu Thomas Coutrot, [...] uma "nova utopia capitalista": a empresa neoliberal" (BRAGA, 2009, p. 68). O que alguns autores conceituam por "empresa neoliberal" ou "empresa moderna" (ANTUNES, 2018, p. 36), é a nova pragmática imposta pelo capital ao mundo do trabalho, marcado por metas, flexibilidade, polivalência e por tarefas controladas pela informatização.

Dentre as transformações que vêm ocorrendo no setor de serviços, observa-se cada vez mais a utilização da tecnologia, como é o caso dos trabalhos em plataforma, que as empresas recorrem ao trabalho digital como forma de baratear a força de trabalho e, consequentemente, aumentar seus lucros, controlar os trabalhadores e também como meio de burlar a legislação trabalhista ao se eximir dos encargos.

Essa era da escravidão digital que permeia o setor de serviços, é propícia - viabilizado pelas TICs - e ao mesmo tempo vital, dentre os mecanismos de acumulação utilizados pelo capital na atualidade, porque gera uma vigilância permanente do trabalho, só que de forma mais explorado e precarizado. A esse movimento do capitalismo "somou-se a terceirização, que também se tornou um instrumento fundamental para o aumento dos lucros, nos setores de telemarketing, call center, fast-food [...]" (ANTUNES, 2020, p.16).

Diante desse cenário de transformações no mundo do trabalho, surge um novo proletariado de serviços na era digital (ANTUNES, 2018). Esse novo contingente de trabalhadores, mesmo com suas diferenciações, faz parte da nova morfologia da classe trabalhadora - desprovido dos direitos protetivos e gerenciados pelas TICs e plataformas digitais - que compreende para além de diversos setores, o de fast-food, como é o caso dos entregadores de aplicativos ${ }^{5}$. 
A nova morfologia do trabalho se insere no quadro social em que a diminuição do tempo de circulação da mercadoria é essencial para o capital atingir altos níveis de acumulação. Assim, diferentemente do trabalhador da indústria - na figura do operário "rígido", realizando sua atividade no uniforme padronizado - o proletário de serviços é, portanto, o proletário digital; àquele trabalhador desprovido dos direitos protetivos, superexplorado, precarizado e que não existe literalmente sem o celular. Isto porque as TICs e as plataformas digitais alteraram enormemente a gestão e os modos de ser do trabalho contemporâneo.

Portanto, a partir do surgimento das TICs, ocorre a intensificação dos processos de precarização da força de trabalho, que cada vez mais reverbera num processo de individualização e num sentimento de não pertencimento da classe trabalhadora, visto que a atual organização do mundo do trabalho digital-informacional contribui para fragmentação - ainda maior - da organização coletiva. Segundo Antunes (2018, p. 59), "uberização, walmartização, intermitência, pejotização, esse será o léxico dominante no mundo do trabalho se a resistência e a confrontação não forem capazes de obstar o vigoroso processo de precarização estrutural do trabalho".

\section{Uberização e empreendedorismo: a fragmentação da organização coletiva da classe trabalhadora}

A nova dinâmica produtiva mediada pelas TICs e plataformas digitais - entendidas como uberização dos processos de trabalho -, criou novas formas de controle e gerenciamento dos trabalhadores, cuja marca está no aprofundamento da precarização e exploração dos trabalhadores e, ainda, a pretensa autonomização dessas relações de trabalho, através da propagação da ideologia empreendedora.

Entende-se essa dinâmica produtiva como sendo uma tendência global que atinge uma diversidade de trabalhadores, localizados tanto no centro quanto na periferia. Essa nova reconfiguração da gestão organizacional, significa mais um passo na intensificação da flexibilização das relações de trabalho, embora persistam ainda as formas mais tradicionais de flexibilização e intensificação do trabalho; como é o caso da terceirização e do trabalho intermitente. De acordo com Antunes (2020, p. 11), “a uberização é um processo no qual as relações de trabalho são crescentemente individualizadas e invisibilizadas, assumindo, assim, a aparência de "prestação de serviços' e obliterando as relações de assalariamento e de exploração do trabalho".

Portanto, ao invés de liberdade, autonomia e flexibilidade, o que está em curso com o atual capitalismo informacional digital uberizado, é uma maior subordinação e controle do trabalho. Nessa lógica, por meio das plataformas digitais, as empresas - seja ela como a Amazon, uma plataforma de micro trabalho que os trabalhadores, com acesso à internet, podem realizar o trabalho em casa, por exemplo, ou seja ela do tipo em que seus trabalhadores estão espraiados nas ruas, como é o caso dos deliverys (Rappi, Ifood e Uber Eats) - controlam o tempo, o deslocamento e o comportamento dos trabalhadores, de modo que aumentam a apropriação do mais valor absoluto e relativo.

Baseado nisso, as empresas Rappi, Ifood e o Uber Eats seguem essa lógica organizacional do trabalho, característico da Indústria 4.0. Normalmente, as entregas são realizadas utilizando veículo próprio do trabalhador como, carro, moto ou bicicleta convencional e, ainda, é preciso ter um smartphone. É válido destacar que além desses, no Ifood, pode ser utilizado bicicleta e patinete elétrico ${ }^{6}$ como meio de transporte, e no Uber Eats, podem ser entregues pedidos a pé . Observa-se que para além do intenso dispêndio de energia física a que o trabalhador está submetido nessa relação capital-trabalho, a superexploração da força de trabalho e a influência do empreendedorismo também se faz presente.

Com o avanço das TICs, o que se observa nesse universo das plataformas é um gerenciamento da força de trabalho de modo online. Logo, essas plataformas ${ }^{8}$ não atuam sozinhas e, portanto, não devem ser consideradas como neutras, visto que "dependem de uma imbricação de algoritmos" e dados, ligados à financeirização e à racionalidade neoliberal" (GROHMANN, 2020, p. 96).

Assim, uberização ou plataformização do trabalho se dá em um setor que está em pleno desenvolvimento e que pode ser intitulado como oriundo da economia do compartilhamento ${ }^{10}$ (sharing economy). Segundo Tom Slee (2017, p.34), essa economia é um fenômeno advindo do Vale do Silício e "promete ajudar prioritariamente indivíduos vulneráveis a tomar controle de suas vidas tornando-os microempresários".

Diferentemente das promessas do capital com a chamada economia do compartilhamento, o que está em andamento é mais um movimento de desregulação dos mercados, em que as empresas-aplicativo utilizam as plataformas para se descomprometer com os custos das regulações da força de trabalho. Esse cenário no 
qual acomete os trabalhadores, só se torna possível porque o Estado - com a contrarreforma trabalhista ${ }^{11}$ preparou uma antessala com a figura do trabalhador intermitente e, também, promove cotidianamente o discurso da ideologia empreendedora, que nada mais é do que uma forma oculta de trabalho assalariado, apresentada como trabalho autônomo.

No contexto de uberização do trabalho, fica nítido a noção do indivíduo que é "empresa de si mesmo" - em que os trabalhadores seguem uma ótica de que são responsáveis pela sua saúde, pelo seu trabalho, pelos seus horários. É por meio dessa ideologia que se acentuam não só as formas de trabalho precário na contemporaneidade, como é o caso dos Entregadores de Aplicativos, - regidos pelas plataformas digitais - como também mascaram as contradições existentes na relação capital-trabalho. Assim, os trabalhadores aparecem como "patrão de si", o que implica no desaparecimento da relação subordinada, acarretando em uma "multidão de empreendedores de si próprios" (ABÍLIO, 2019, p. 4). Na ótica do capitalismo de plataforma, todos os trabalhadores passam a ser chamados de "colaboradores", "parceiros"12 e, conforme Alves (2007, p.172), "supostamente pessoas livres, juridicamente iguais".

Fica evidente, então, que a ideologia do empreendedorismo é partícipe e central nos diversos trabalhos uberizados. Logo, não passa de um discurso que diversas empresas utilizam e propagam na tentativa de não só individualizar, mas baratear a força de trabalho. Dessa forma, o que está ocorrendo no atual mundo do trabalho, são milhares de trabalhadores plataformizados ${ }^{13}$ exercendo seus trabalhos desprotegidos e tidos como livres; empreendedores e autônomos, quando seguem, na prática, tendo seu trabalho subordinado e controlado pelo capital.

Para além disso, as ideias propagadas pela ideologia empreendedora de que o trabalhador pode ser o seu próprio chefe ou gerenciar o seu próprio negócio, interfere diretamente na organização dos trabalhadores de plataformas, aqui os entregadores de aplicativos, uma vez que eles passam a se reconhecer como patrão e não mais como classe trabalhadora, se distanciando das lutas coletivas. "O/a "empreendedor/a" se imagina, por um lado, como "proprietário/a de si mesmo", enquanto em sua concretude e efetividade, por outro, converte-se em "proletário/a de si próprio" (FILGUEIRAS; ANTUNES 2020, p. 77).

Destaca-se os entregadores de aplicativos porque o contexto de crise pandêmica do Covid-19 agudizou as condições de trabalho que esses estão inseridos. Isso porque a crise sanitária intensificou e tornou mais transparente o trabalho de delivery - que já era superexplorado - no instante em que os entregadores passaram a arriscar suas vidas e de suas famílias nessa atividade laboral que é essencial para contribuir com a manutenção do isolamento social. Nesse sentido, a fala do entregador Diógenes de Souza (2020 apud SUDRÉ, 2020) que trabalha para empresas-aplicativo, em entrevista cedida ao Brasil de Fato, revela que durante a pandemia não tirava um dia para descansar, trabalhava diariamente das 10 horas da manhã às 23 horas da noite. E, ainda, expõe também que mesmo estando diariamente disponível para o trabalho, sua remuneração era baixa.

Assim, tomando como base o pensamento de Dal Rosso (2012), de que uma das formas de intensificação do trabalho é através da administração por resultados, isto é, metas, verifica-se também a existência desse formato no trabalho dos entregadores de aplicativos. De acordo com a reportagem da UOL (BONIS, 2020, p. 1), por exemplo, um entregador precisa trabalhar mais para ganhar o mesmo que recebia há alguns meses "antes da pandemia, sua meta diária de 200 reais era viável. Hoje, está difícil chegar a 100 reais, conta". Isto em decorrência da alta demanda pelas empresas-aplicativo e também pelo aumento de entregadores nas ruas, o que acirra o cenário de competitividade por entregas. A empresa Rappi, por exemplo, chegou a registrar pico de $300 \%$ de crescimento no número de pedidos de cadastro de entregadores no aplicativo (SALOMÃO, 2020, p. 1).

$\mathrm{Na}$ contrapartida desse panorama de precarização das condições de trabalho dos entregadores, que se agravou com a crise sanitária e tem refletido no aumento das jornadas de trabalho e no rebaixamento salarial, nota-se a ampliação das taxas de lucro das empresas-aplicativo. De acordo com dados da revista Exame (CRISE..., 2020), a startup colombiana Rappi teve aumento de cerca de $30 \%$ no número de pedidos em toda América Latina nos dois primeiros meses de 2020 em relação aos dois últimos de 2019, principalmente para os setores, dentre outros, de restaurantes e supermercados. No Brasil, entre 20 de fevereiro e 16 de março de 2020 , os downloads de aplicativos de entrega cresceram $24 \%$ em relação ao mesmo período do ano passado e o pico de instalações ocorreu em 6 de março de 2020, um aumento de $126 \%$ em relação ao mesmo dia em 2019 (MEIRELES, 2020). 
A entrada dos aplicativos - por meio das TICs - na reorganização do mundo do trabalho atualmente, vem acarretando não só no rebaixamento dos salários dos trabalhadores - em decorrência da substituição massiva do trabalho vivo pelo trabalho morto - como também na dificuldade dos entregadores de aplicativos se organizar e mobilizar para frear as diversas expropriações que vem sofrendo através da competição criada pelas empresas-aplicativo.

Assim, "a existência de poucos locais físicos de encontro dos trabalhadores e trabalhadoras das empresas plataformas" (GONSALES, 2020, p. 133), com horários e uma rotina de trabalho fixa, faz com que os trabalhadores fiquem cada vez mais dispersos, não existindo àquela sociabilidade ao chegar, no intervalo ou até mesmo na saída do local de trabalho. Isso acarreta de maneira significativa na fragmentação dos entregadores, uma vez que são nesses momentos do cotidiano que os trabalhadores conseguem mais rapidamente se mobilizar e articular diante dos ataques feitos pelos empregadores à classe trabalhadora.

Outro fator que dificulta a organização coletiva pode ser compreendido através de um conceito bem característico dos trabalhos uberizados, conhecido como trabalho amador, em que Abílio (2019 apud SANTOS, 2019 , p. 1) trata o amadorismo como sendo "um trabalho que opera e aparece como trabalho, mas que não confere identidade profissional, não se forma como profissão, tem alta maleabilidade e flexibilidade na sua própria caracterização".

Essa perda da identidade ocorre porque as empresas-aplicativo atuam de modo informal e sem regulamentações, ou seja, os entregadores de aplicativos, sejam bikeboys ou motoboys, não necessitam de muitas determinações para exercerem suas atividades, eles podem ser estudantes durante o dia e/ou trabalhadores, e à noite realizar entregas. É essa maleabilidade ou identidade provisória que oblitera a organização desses trabalhadores.

E, ainda, outros fatores que também dificultam a tomada de consciência de classe nos trabalhos uberizados, são, de acordo com Gonsales (2020, p.133) "“...] 2) o fato de que parte da classe atua apenas quando necessário para complementar sua renda; [... 5) a dinâmica dos vínculos com diversos empregadores; 6) os recursos limitados a uma sobrevivência às margens do sistema"

Portanto, há uma tendência devastadora que vem assolando não só, mas principalmente o mundo do trabalho, com a inserção de formas extremamente precárias de trabalho - compactuada com o Estado e com o avanço tecnológico. Logo, se isso não for freado, "teremos a ampliação exponencial da informalidade no mundo digital, a expansão dos trabalhos 'autônomos', dos "empreendedorismos" (ANTUNES, 2020, p. 15).

É válido ressaltar que, apesar do contexto de precariedade em que os entregadores de aplicativos estão inseridos, eles vêm conseguindo dialogar - por meio das redes sociais - e desenvolver formas de organização e luta frente aos mecanismos de controle utilizado pelas empresas de delivery. Prova disso, foram as paralisações dos Entregadores de Aplicativos que aconteceram no dia $1^{\circ}$ e no 25 de julho de 2020, em que o movimento ficou conhecido como Breque dos Apps (ACCARINI, 2020), e que trouxe à tona nacionalmente a precarização do trabalho dessa categoria - que se agravou ainda mais com a crise sanitária mundial da Covid-19 - que atua para empresas-plataforma como Ifood, Rappi e Uber Eats. A paralisação culminou para além das ruas, visto que os entregadores tiveram não só o apoio da população - ao não realizarem pedidos nas plataformas durante o dia - como também da Confederação Nacional dos Trabalhadores em Transportes e Logísticas da CUT (CNTTL) em conjunto com a Federação Nacional dos Trabalhadores Motociclistas Profissionais Autônomos (FENAMOTO), declararam apoio ao movimento dos entregadores de aplicativo (ACCARINI, 2020).

É necessário pontuar que a adesão a essa mobilização dos entregadores precisa ser tecida cotidianamente, para que haja continuidade na luta da organização coletiva frente às condições precárias de trabalho que estão sendo submetidas pelos aplicativos. O Breque dos Apps evidenciou para a sociedade a corrosão de maneira célere das "condições de trabalho provocado pela perversa combinação entre a lógica neoliberal e a adoção de um novo modelo de negócios que, com o auxílio da tecnologia, é concebido para promover a burla de direitos em favor do capital" (RIBEIRO, 2020, p. 1).

Diante disso, é no sentido de frear as condições "flexíveis" de trabalho, imposta pelas plataformas aos trabalhadores e fortalecer também a mobilização dessa categoria na luta de classe, que já estão em curso "novas formas de organização política que envolvem a criação de sindicatos de aplicativos [...]" (ABÍLIO, 2020, p. 121). Isto já vem ocorrendo no Brasil como é o caso, por exemplo, "do Sindicato dos Motoristas por Aplicativo e Condutores de Cooperativas do Estado da Bahia (Simactter-BA); e o Sindicato dos Motoristas 
de Transporte Privado Individual de Passageiros por Aplicativo do Estado de Pernambuco (Simtrapli-PE)", conforme colocou Grohmann (2020, p. 107).

Cabe explicitar que as lutas e mobilizações dos entregadores de aplicativos que iniciaram de forma "isolada" - sendo composta majoritariamente por trabalhadores que laboram na mesma categoria - vem ganhando um espaço maior nas lutas coletivas, em que trabalhadores ligados a outros setores estão se unindo e lutando conjuntamente, o que mostra uma nova fase da organização coletiva.

Portanto, é imprescindível a continuidade de mobilizações das categorias frente a uma luta coletiva da classe trabalhadora para que esse sistema precário, desumano e explorador do capital não se torne cada vez mais central, tendo em vista que a história mostra que as vitórias da classe trabalhadora só têm sido alcançadas por meio da luta de classes, como disse Marx e Engels (2008).

\section{Considerações finais}

O fenômeno da uberização surge no contexto de alterações no mundo do trabalho, em que o capital necessitou encontrar novas formas, por meio das TICs, para ampliar seus lucros e acumular mais riqueza. Contexto marcado pela reestruturação produtiva e pelas contrarreformas do Estado - pautadas pela agenda neoliberal, em síntese, formas de flexibilização da produção e da gestão do trabalho, em que ao mesmo tempo ocorre a ampliação de modalidades de trabalhadores informais, desprotegidos e desregulamentados.

Verificou-se, pois, como sendo partícipe do trabalho uberizado, a ideologia empreendedora, que apoiada nas TICs, é exposta na mídia burguesa como sinônimo de trabalho autônomo, mas que na realidade é uma modalidade de trabalho informal na contemporaneidade.

A inserção das TICs no trabalho dos entregadores de aplicativos junto ao discurso empreendedor, na verdade, é uma reatualização das formas de cooptação e controle da força de trabalho pelo capital, que tende incessantemente a utilizar artifícios linguísticos para além de precarizar, fragmentar as mobilizações de lutas coletivas; uma vez que esses acabam por não se reconhecerem mais como pertencentes da classe trabalhadora.

Evidenciou-se, assim, que apesar do discurso da ideologia empreendedora e dos mecanismos de controle e gerenciamento algorítmico utilizado pelas empresas-plataforma - que objetivam individualizar e desmobilizar a organização destes - os entregadores de aplicativos vêm construindo mobilizações coletivas, reivindicando por seus direitos.

Logo, colocamos como uma tendência que os entregadores vêm conseguindo se mobilizar e articular, constatando que o que se iniciou de forma isolada, tem ganhado desdobramentos posteriores - com as greves - em vários Estados do Brasil, com o apoio além da sociedade, de algumas centrais sindicais, como a CUT.

Por fim, é possível evidenciar que, com o chamado capitalismo de plataforma, está em curso uma nova fase da organização coletiva da classe trabalhadora. Diante de um cenário político ultraneoliberal - agudizado pelo cenário pandêmico -, os trabalhadores vêm se articulando e reivindicando melhores condições de trabalho e vida. A história tem movimento e como poetizou Brecht (1982) - "nada deve parecer impossível de mudar".

\section{Referências}

ABÍLIO, L. Uberização: Do empreendedorismo para o autogerenciamento subordinado. Psicoperspectivas, Goiás, vol. 18 n. 3 , p. 111, 2019. Disponível em: https://scielo.conicyt.cl/pdf/psicop/v18n3/0718-6924-psicop-18-03-41.pdf. Acesso em: 20 de jan. 2021.

ABÍLIO, L. Uberização: gerenciamento e controle do trabalhador just-in-time. In: ANTUNES, R (Org). Uberização, trabalho digital e indústria 4.0. São Paulo: Boitempo Editorial, 2020, p.111-124.

ACCARINI, A. Entregadores de aplicativos pedem que sociedade participe da greve neste sábado, 25. CUT - Central Única dos Trabalhadores, Brasil, 24 jul. 2020. Disponível em: https://www.cut.org.br/noticias/entregadores-de-aplicativos-pedem-que-sociedadeparticipe-da-greve-neste-sabado-21d3. Acesso em: 3 set. 2021.

ALVES, G. Dimensões da Reestruturação Produtiva: ensaios de sociologia do trabalho. Londrina: Práxis, 2007.

ANTUNES, R. O privilégio da servidão: o novo proletariado de serviços na era digital. São Paulo: Boitempo Editorial, 2018.

ANTUNES, R. Trabalho intermitente e uberização do trabalho no limiar da indústria 4.0. In: ANTUNES, R (Org). Uberização, trabalho digital e indústria 4.0. São Paulo: Boitempo Editorial, 2020, p.11-22. 
BONIS, G. Pandemia precariza ainda mais o trabalho de entregadores de aplicativos. UOL Economia, [São Paulo], 10 jul. 2020. Disponivel em: https://economia.uol.com.br/noticias/redacao/2020/07/10/pandemia-precariza-ainda-mais-o-trabalho-de-entregadoresde-aplicativos.htm. Acesso em: 3 set. 2021.

BRAGA, R. A vingança de Braverman: o infotaylorismo como contratempo. In: ANTUNES, R; BRAGA, R. (Orgs). Infoproletários: degradação do trabalho virtual. São Paulo: Boitempo, 2009. p. 59-88.

BRASIL. Lei n 13.429 , de 31 de março de 2017. Altera dispositivos da Lei n o 6.019, de 3 de janeiro de 1974, que dispõe sobre o trabalho temporário nas empresas urbanas e dá outras providências; e dispõe sobre as relações de trabalho na empresa de prestação de serviços a terceiros. Brasília, DF: Presidência da República, [2017a]. Disponível em: http://www.planalto.gov.br/ccivil_03/_ato20152018/2017/lei/113429.htm. Acesso em 3 set. 2021.

BRASIL. Lei ${ }^{\circ}$ 13.467, de 13 de julho de 2017. Altera a Consolidação das Leis do Trabalho (CLT), aprovada pelo Decreto-Lei ${ }^{\circ}$ 5.452 , de $1^{\circ}$ de maio de 1943, e as Leis ${ }^{\circ}{ }^{6} 6.019$, de 3 de janeiro de 1974, 8.036, de 11 de maio de 1990, e 8.212, de 24 de julho de 1991, a fim de adequar a legislação às novas relações de trabalho. Brasília, DF: Presidência da República, [2017]. Disponível em: http://www.planalto.gov.br/ccivil_03/_ato2015-2018/2017/lei/113467.htm. Acesso em: 3 set. 2021.

BRECHT, B. Antologia poética. Rio de Janeiro: ELO Editora, 1982.

CRISE do coronavírus impulsiona aplicativos de entregas no Brasil. Exame, Brasil, 17 mar. 2021. Disponível em: https://exame.com/ negocios/crise-do-coronavirus-impulsiona-aplicativos-de-entregas-no-brasil/. Acesso em: 3 set. 2021.

DAL ROSSO, S. Mais trabalho! A intensificação do labor na sociedade contemporânea. São Paulo: Boitempo Editora, 2012.

DEFESA dos direitos sociais e da regulamentação da contratação por meio de aplicativos é destaque em debate sobre futuro do trabalho. Sexta edição do Simpósio "Futuro do Trabalho: os Efeitos da Revolução Digital na Sociedade" aconteceram nesta quinta-feira (11/7), em Brasília. Escola Superior do Ministério Público da União, Brasília, 12 jul. 2019. Disponível em: http://escola.mpu.mp.br/a-escola/ comunicacao/noticias/defesa-dos-direitos-sociais-e-da-regulamentacao-da-contratacao-por-meio-de-aplicativos-e-destaque-em-debatesobre-futuro-do-trabalho. Acesso em 3 set. 2021.

FACHIN, P. O proletário digital na era da reestruturação permanente do capital. Entrevista especial com Ricardo Antunes. Instituto Humanitas Unisinos, São Leopoldo, 21 ago. 2018. Disponível em: http://www.ihu.unisinos.br/159-noticias/entrevistas/582010-oproletario-digital-na-era-da-reestruturacao-permanente-do-capital-entrevista-\%20especial-com-ricardo-antunes. Acesso em: 13 fev. 2021.

FAGIANI, C. C.; PREVITALI, F. S. Trabalho digital e educação no Brasil. In: ANTUNES, R (Org). Uberização, trabalho digital e indústria 4.0. São Paulo: Boitempo Editora, 2020, p. 217-235.

FILGUEIRAS, V; ANTUNES, R. Plataformas digitais, uberização do trabalho e regulação no capitalismo contemporâneo. In: ANTUNES, R (Org). Uberização, trabalho digital e indústria 4.0. São Paulo: Boitempo Editorial, 2020, p.59-78.

GONSALES, M. Indústria 4.0: empresas plataformas, consentimento e resistência. In: ANTUNES, R (Org). Uberização, trabalho digital e indústria 4.0. São Paulo: Boitempo Editorial, 2020, p. 125-137.

GROHMANN, R. Plataformização do trabalho: características e alternativas. In: ANTUNES, R (Org). Uberização, trabalho digital e indústria 4.0. São Paulo: Boitempo Editorial, 2020, p. 93-109.

LABORATÓRIO do Futuro publica o Relatório técnico "O Futuro do Emprego no Brasil: estimando o impacto da automação". Laboratório do Futuro, Brasil, ago. 2019. Disponível em: http://labfuturo.cos.ufrj.br/laboratorio-do-futuro-publica-o-relatorio-tecnicoo-futuro-do-emprego-no-brasil-estimando-o-impacto-da-automacao/. Acesso em: 13 fev. 2021.

MARX, K; ENGELS, F. Manifesto do partido comunista. São Paulo: Expressão Popular, 2008.

MEIRELES, L. Quarentena pelo coronavírus impacta downloads de aplicativos de entregas. Consumidor Moderno, São Paulo, 24 mar. 2020. Disponível em: https://www.consumidormoderno.com.br/2020/03/24/quarentena-coronavirus-impacta-aplicativos-entregas/. Acesso em: 3 set. 2021.

PINTO, G. A indústria 4.0 na cadeia automotiva: a Mercedes-Benz em São Bernardo do Campo. In: ANTUNES, R. (Org). Uberização, Trabalho Digital e Indústria 4.0. São Paulo: Boitempo, 2020. p. 193-216.

RIBEIRO, F. A greve e as perspectivas do movimento entregadores. Remir Trabalho, Brasil, 23 jul. 2020. Disponivel em: https:// www.eco.unicamp.br/remir/index.php/sindicalismo/189-a-greve-e-as-perspectivas-do-movimento-\%20entregadores\#_ftn1. Acesso em: 3 set. 2021.

SALOMÃO, K. iFood e Rappi: mais entregadores (e mais cobrança por apoio) na pandemia. Exame, Brasil, 20 abr. 2020. Disponivel em: https://exame.com/negocios/coronavirus-leva-mais-entregadores-e-gorjetas-aos-apps-de-delivery/. Acesso em: 3 set. 2021.

SANTOS, J. V. Na Revolução 4.0, automação ameaçará postos de trabalho mais rapidamente. Entrevista especial com Bruno Ottoni Eloy Vaz. Instituto Humanitas Unisinos, São Leopoldo, 9 jan. 2020. Disponível em: http://www.ihu.unisinos.br/595444-na-revolucao4-0-automacao-ameacara-postos-de-trabalho-mais-\%20rapidamente-entrevista-especial-com-bruno-ottoni-eloy-vaz. Acesso em: 13 fev. 2021. 
SANTOS, J. V. Uberização: a edição da velha ideia do trabalho amador. Entrevista especial com Ludmila Abílio. Instituto Humanitas Unisinos, São Leopoldo, 13 ago. 2019. Disponível em: http://www.ihu.unisinos.br/159-\%20noticias/entrevistas/591603-uberizacaoa-edicao-da-velha-ideia-do-trabalho-amador-entrevista-especial-com-\%20ludmila-abilio. Acesso em: 3 set. 2021.

SLEE, T. Uberização: a nova onda do trabalho precarizado. São Paulo: Elefante, 2017.

SUDRÉ, L. Jornadas de 12h e zero direitos: por que entregadores de apps fazem greve inédita. Brasil de Fato, São Paulo, 30 jun. 2020. Disponível em: https://www.brasildefato.com.br/2020/06/30/12h-de-trabalho-sem-apoio-e-sem-direitos-o-dia-a-dia-dos-entregadoresde-apps. Acesso em: 30 jun. 2021.

UBER. Faça entregas pelo app do Uber Eats. Osasco SP, 2021. Disponível em: https://www.uber.com/br/pt-br/deliver/. Acesso em: 13 fev. 2021

WOLFF, S. O "trabalho informacional” e a reificação da informação sob novos paradigmas organizacionais. In: ANTUNES, R; BRAGA, R. (Orgs). Infoproletários: degradação do trabalho virtual. São Paulo: Boitempo Editorial, 2009. p. 89-112.

\section{Notas}

1 O proletariado digital na era da reestruturação permanente do capital. Entrevista especial com Ricardo Antunes. Instituto Humanitas Unisinos, 21 agos. 2018.

2 Segundo Antunes (2020, p. 13), "as tecnologias de informação e comunicação configuram-se, então, como um elemento central entre os distintos mecanismos de acumulação criados pelo capitalismo financeiro de nosso tempo".

3 Para mais informações sobre a Indústria 4.0, ver o artigo Pinto (2020).

4 Segundo Wolff (2009, p. 107), "a informatização nada mais é que um modo de gerir a informação mediante os recursos possibilitados pela TICs [...]".

5 De acordo com a pesquisa sobre o "Levantamento sobre o Trabalho dos Entregadores por Aplicativos no Brasil", pôde-se traçar um perfil dos entregadores para melhor compreender suas características. O perfil dos entregadores é composto, majoritariamente, por homens (95\%), jovens de até 30 anos de idade (56,5\%) e negros $(59,2 \%)$. (LEVANTAMENTO... 2020, p. 8)

6 Aluguel disponível em alguns lugares e com possível expansão. Vale ressaltar que é uma forma ilegal de casadinha, visto que o trabalhador é forçado a assinar algum plano semanal para assim ter acesso a um ponto de apoio do Ifood com banheiro, microondas, água etc.

7 De acordo com o site da Uber, somente na cidade de São Paulo (UBER, 2021)

8 "Plataformas digitais" ou 'Aplicativos' são infraestruturas combinadas de softwares e hardwares, de propriedade privada ou pública, alimentadas por dados, automatizadas por meio de algoritmos digitais" (CASILLI; POSADA, 2019 apud GONSALES, 2020, p. 125). Cabe pontuar também, de acordo com Grohmann (2020, p. 100), que "a plataformização do trabalho, [...], envolve a dependência que trabalhadores e consumidores passam a ter das plataformas digitais - com suas lógicas algorítmicas, dataficadas e financeirizadas - somada a mudanças que intensificam a flexibilização de relações e contratos de trabalho [...]".

9 Segundo Abílio (2020, p. 1), "é a possibilidade de traduzir modos de vida, relações sociais, trajetórias e desigualdades em dados administráveis que produzirão e reproduzirão desigualdades e mecanismos de exploração do trabalho".

10 Não há um consenso entre os autores se economia do compartilhamento seria o melhor termo para se usar. Assim, outros termos seriam: "consumo colaborativo" (collaborative consumption), "economia em rede" (mesh economy), plataformas igual - para igual (peer- to - peer platforms), "economia dos bicos" (gig economy), economia da viração, serviços de concierge ou economia sob demanda (on-demand economy) (SLEE, 2017, p. 36).

11 Mesmo sabendo que as contrarreformas, no Brasil, podem ser percebidas ao longo dos anos 2000, faz-se referência aqui a reforma trabalhista - regulamentada pela Lei de $\mathrm{n}^{\circ}$ 13.467/2017 (BRASIL, [2017]), que altera a Constituição das Leis Trabalhistas (CLT) e a Lei de Terceirização - Lei de nº 13.429/2017 (BRASIL, [2017a]), aprovada no governo de Michel Temer. Consideramos esta reforma por aprofundar os ataques nas legislações que regulamentam o trabalho, tornando-o mais suscetível à exploração do capital.

12 Mecanismos linguísticos utilizados pelas empresas-aplicativo para obscurecer a relação de subordinação dos entregadores de aplicativos nesse trabalho informal.

13 Estima-se que 3,8 milhões de pessoas têm o trabalho mediado por plataformas, principalmente trabalhadores e trabalhadoras das empresas de transporte particular por aplicativo, e de entregas de alimentos e produtos em geral, e quem "emprega" toda essa força de trabalho são as empresas Uber, 99, Ifood e Rappi. (DEFESA..., 2019). 


\title{
Nathalia Tamiris Carvalho de Luna
}

ntcluna@hotmail.com

Graduada em Serviço Social pela Universidade Federal de Pernambuco (UFPE)

Pesquisadora do Grupo de Estudos e Pesquisas sobre o Trabalho (GET-UFPE)

\section{Ariadne Samila Martins de Oliveira}

ariadne.samila@hotmail.com

Graduada em Serviço Social pela Universidade Federal de Pernambuco (UFPE)

Pesquisadora do Grupo de Estudos e Pesquisas sobre o Trabalho (GET-UFPE)

\section{UFPE}

Av. Prof. Moraes Rego, 1235, Cidade Universitária

Recife - PE - Brasil

CEP: 50.670-901

\author{
Agradecimentos \\ Às nossas professoras Angela Santana do Amaral e Juliane \\ Feix Peruzzo, por nos aproximarem de temáticas que versam \\ sobre o mundo do trabalho, desde a nossa entrada na Iniciação \\ Científica (IC), como também no momento de realização do \\ Trabalho de Conclusão de Curso (TCC), que culminou neste \\ artigo. \\ Agência financiadora \\ Não se aplica. \\ Contribuições das autoras \\ Este artigo foi realizado em coautoria e a temática é de \\ interesse de ambas autoras. A autora foi responsável pela
}

\author{
discussão sobre o setor de serviços, o empreendedorismo e pela \\ parte da revisão gramatical e de normas da ABNT. A coautora \\ contribuiu com o debate sobre a indústria 4.0 e a fragmentação \\ da classe trabalhadora. \\ Aprovação por Comitê de Ética e consentimento para \\ participação \\ Não se aplica. \\ Consentimento para publicação \\ Consentimento das autoras. \\ Conflito de interesses \\ Não há conflito de interesses.
}

